Ambiente \& Água - An Interdisciplinary Journal of Applied Science
ISSN 1980-993X - doi:10.4136/1980-993X
www.ambi-agua.net
E-mail: ambi-agua@agro.unitau.br

\title{
Correlação entre condição da superfície do solo agrícola e o coeficiente de absorção acústica
}

\author{
doi: 10.4136/ambi-agua.1423
}

Received: 12 Jun. 2014; Accepted: 13 Aug. 2014

\author{
Rosane Freire $^{1 *}$; Célia Regina Granhen Tavares²; Paulo Fernando Soares ${ }^{3}$; \\ Marco Henrique Meletti de Abreu ${ }^{4}$ \\ ${ }^{1}$ Universidade Estadual Paulista "Júlio de Mesquita Filho" (UNESP), Presidente Prudente, SP, Brasil \\ Departamento de Física, Química e Biologia \\ ${ }^{2}$ Universidade Estadual de Maringá (UEM), Maringá, PR, Brasil \\ Departamento de Engenharia Química \\ ${ }^{3}$ Universidade Estadual de Maringá (UEM), Maringá, PR, Brasil \\ Departamento de Engenharia Civil \\ ${ }^{4}$ Universidade de São Paulo (USP), São Paulo, SP, Brasil \\ Departamento de Geografia \\ *Autor correspondente: e-mail: rofreire@gmail.com, \\ celiagranhen@gmail.com, paulofsoares@gmail.com, \\ marcohenriquema@gmail.com
}

\section{RESUMO}

Objetivou-se com esse trabalho aplicar a técnica acústica com o intuito de relacionar a resposta de um sinal sonoro emitido em diferentes superfícies, medido em nível de pressão sonora equivalente, com os fatores que regem a perda de solos. Em campo foram construídas quatro parcelas em escala reduzida, com dimensões de 2,0 x 12,5 m, com diferentes usos (rugosidades). Em relação ao tipo de cobertura, uma parcela permaneceu com solo exposto e as demais com pastagem (Brachiaria), cultura de milho e com cultura temporária de soja/trigo, seguindo as práticas agrícolas sazonais implantadas na bacia hidrográfica na qual o estudo foi realizado. Para o sistema acústico, utilizou-se o ruído rosa nas medições do monitoramento proposto, coletando informações sobre o nível de pressão sonora equivalente $\left(\mathrm{L}_{\mathrm{EQ}}\right)$ das ondas incidentes e refletidas. Em relação aos ensaios acústicos, os resultados apontaram que não houve diferenciação entre o tipo de cobertura do solo instaladas nas parcelas erosivas e o coeficiente de absorção acústico medido em $\mathrm{L}_{\mathrm{EQ}}$.

Palavras-chave: perda de solo, nível de pressão sonora equivalente $\left(\mathrm{L}_{\mathrm{EQ}}\right)$, ruído rosa.

\section{Correlation between condition of agricultural soil surface and the sound absorption coefficient}

\begin{abstract}
This work applied acoustic technique to relate the response of a signal sound to different surfaces, measured in equivalent sound pressure level, with the factors governing soil loss. Four erosion plots in reduced scale $(2.0 \times 12.5 \mathrm{~m})$ were built on the field. One plot contained
\end{abstract}


barren soil while the others contained forage grass (Brachiaria), corn and temporary crop soybean/wheat, following the seasonal agricultural practices implemented in the watershed where the study was conducted. Pink noise was used in the measurements of the acoustic system to collect information regarding the equivalent sound pressure level $\left(\mathrm{L}_{\mathrm{EQ}}\right)$ of incident and reflected waves. The results of the noise tests indicated that there was no differentiation between the type of ground cover and the acoustic absorption coefficient measured in $\mathrm{L}_{\mathrm{EQ}}$.

Keywords: equivalent sound pressure level $\left(\mathrm{L}_{\mathrm{EQ}}\right)$, loss of soil, pink noise.

\section{INTRODUÇÃO}

As avaliações experimentais diretas e, portanto, mais confiáveis dos fatores que governam a perda de solo, de acordo com as normas preconizadas na literatura, além de demandarem excessivos gastos também exigem muito tempo nas suas determinações. Contudo, sem ainda chegar a uma metodologia consistente e que leve à obtenção de dados confiáveis, a determinação indireta da perda de solo vêm apresentando uma série de limitações às quais inspiram várias pesquisas.

Embora não muito empregada em prática, a técnica acústica possui algumas finalidades na determinação de propriedades dos solos. Os estudos sobre o assunto são relativamente recentes, datam do final da década de 60 e tem despertado a atenção da comunidade científica por ser um método rápido, de baixo custo, fácil de utilizar e com alto potencial de aplicação direta em campo.

Vitorino et al. (2001) utilizaram o ultrassom para a dispersão de argila na análise granulométrica. Carolino de Sá et al. (2002) empregaram a técnica para a determinação de estabilidade de agregados em Latossolos e Nitossolos e, Ribeiro et al. (2009) estudaram a relação entre a desagregação de amostras de solo pela energia ultrassônica, como efeito de desagregação do solo causado pela energia cinética de gotas de chuvas.

Do ponto de vista da agricultura, Sharma e Gupta (2010) determinaram a umidade do solo utilizando a resposta de um sinal acústico de sensor portátil e estimaram efeito do teor de água sobre a velocidade do som em um solo com textura variando de silto-argilosa para arenosa utilizando ondas acústicas contínuas.

Em um posicionamento voltado para a conservação do solo, Chambers e Sabatier (2002) propuseram utilizar a acústica como um método de mensuração da rugosidade da superfície do solo de modo que ela possa ser devidamente inclusa como mais um fator da Equação Universal da Perda de Solo (EUPS). Os testes laboratoriais foram realizados utilizando materiais com diferentes tamanhos de grão (pequeno, médio e grande). O teste em campo (in situ) foi realizado um experimento em um local recentemente arado, apresentando diferentes tamanhos de torrões, proporcionando uma escala de pequena, média e grande rugosidade. No experimento, os resultados obtidos em campo mostraram efeitos proporcionais aos testes obtidos no laboratório, ou seja, houve atenuação do sinal emitido nos diferentes materiais estudados sendo possível correlacionar o tamanho do grão com o grau de rugosidade medido.

A hipótese que rege é a de que utilizando o mesmo princípio técnico, seria igualmente possível relacionar a rugosidade superficial de determinado tipo de uso do solo com o valor de reflexão de um sinal sonoro por ela emitida. Desse modo, o presente estudo tem por objetivo propor a aplicação da relação entre a resposta de um sinal sonoro emitido por diferentes superfícies agrícolas (rugosidades), medido em nível de pressão sonora equivalente ( $\left.\mathrm{L}_{\mathrm{EQ}}\right) \mathrm{com}$ os fatores da perda de solos. Espera-se elucidar uma ferramenta importante, rápida e precisa no levantamento e determinação de fatores que regem a perda de solos e que visa, acima de 
tudo, contribuir com o avanço dos estudos e inserção de novas tecnologias na área ambiental, focando a preservação e conservação dos recursos naturais.

\section{FUNDAMENTAÇÃO DA TEORIA E CÁLCULOS}

\subsection{Perda de solo}

$\mathrm{Na}$ formulação da Equação Universal da Perda de Solo (EUPS), Wichmeier e Smith (1978) concluíram empiricamente que a perda de solos de uma determinada área é a relação direta entre a intensidade da chuva (fator de erosividade), as propriedades inerentes ao solo (fator de erodibilidade), o comprimento e o grau do declive da vertente, o uso e manejo adotado e a presença de práticas conservacionistas. Esses fatores combinam-se linearmente, como expresso na Equação (1).

$$
A=R \cdot K \cdot L S \cdot C \cdot P
$$

em que:

$$
\begin{aligned}
& A=\text { perda de solo }\left(\mathrm{Mg} \mathrm{ha}^{-1} \mathrm{ano}^{-1}\right) \text {; } \\
& R=\text { fator de erosividade }\left(\mathrm{MJ} \mathrm{mm} \mathrm{ha}{ }^{-1} \mathrm{ano}^{-1}\right) \text {; } \\
& K=\text { fator de erodibilidade do solo }\left(\mathrm{Mg} \mathrm{MJ}^{-1} \mathrm{~mm}^{-1}\right) \text {; } \\
& L S=\text { fator topográfico do solo, representa o comprimento de rampa (m) e grau de } \\
& C=\text { fator de uso e manejo }\left(\left(\mathrm{Mg} \mathrm{ha}^{-1}\right)\left(\mathrm{Mg} \mathrm{ha}^{-1}\right)^{-1}\right) \text {; } \\
& P=\text { práticas conservacionistas (-). }
\end{aligned}
$$
declive $(\%)$;

Quando os outros fatores da EUPS são mantidos constantes, as perdas de solo ocasionadas pelas chuvas nos terrenos cultivados são diretamente proporcionais ao valor do produto de sua energia cinética $(\mathrm{Ec})$ e sua intensidade máxima em trinta minutos $\left(\mathrm{I}_{30}\right)$, como apresentado na Equação (2).

$$
E I_{30}=E_{c} \cdot I_{30}
$$

em que:

$$
\begin{aligned}
& E I_{30}=\text { índice de erosão }\left(\mathrm{MJ} \mathrm{mm} \mathrm{ha}{ }^{-1} \mathrm{~h}^{-1}\right) ; \\
& E c=\text { energia cinética da chuva }\left(\mathrm{MJ} \mathrm{ha}^{-1} \mathrm{~mm}^{-1}\right) ; \\
& I_{30}=\text { intensidade máxima em } 30 \text { minutos }\left(\mathrm{mm} \mathrm{h}^{-1}\right) .
\end{aligned}
$$

A energia cinética da chuva pode ser calculada pela Equação 3. A soma dos valores dos índices de erosividade $\left(\mathrm{EI}_{30}\right)$ de cada chuva em certo período proporciona uma avaliação numérica do fator erosividade (Fator R) da chuva.

$$
E_{c}=0,119+0,0873 \log I
$$

em que:

$$
I=\text { intensidade da chuva }\left(\mathrm{mm} \mathrm{h}^{-1}\right) .
$$

$\mathrm{O}$ fator de erodibilidade (K) é representado pela relação entre a perda de solo (Fator A) e o fator erosividade da chuva (Fator R), quando tais dados são obtidos em um determinado 
período, como apresentado na Equação (4). Tais quantificações são efetuadas nas condições de parcela padrão e conhecidas como método direto.

$$
\text { Fator } K=\frac{\text { Fator } A}{\text { Fator } R}
$$

em que:

Factor $K=$ fator de erodibilidade do solo pelo método direto $\left(\mathrm{Mg} \mathrm{h} \mathrm{MJ}^{-1} \mathrm{~mm}^{-1}\right)$;

Factor $A=$ perda de solo $\left(\mathrm{Mg} \mathrm{ha}^{-1}\right)$;

Factor $R=$ fator de erosividade $\left(\mathrm{MJ} \mathrm{mm} \mathrm{ha}{ }^{-1} \mathrm{~h}^{-1}\right)$.

A intensidade da erosão hídrica é afetada tanto pela distância ao longo do qual se processa o escoamento superficial quanto pela declividade do terreno, representados pelo fator topográfico (LS). Este fator pode ser determinado experimentalmente e a Equação 5 mostra a estimativa apresentada em Bertoni e Lombardi Neto (2010).

$$
L S=\frac{\sqrt{L}}{100} \cdot\left(1,36+0,97 \cdot S+0,1385 \cdot S^{2}\right)
$$

em que:

$L=$ comprimento do declive $(\mathrm{m})$;

$S=$ grau do declive $(\%)$.

O fator de uso e manejo (C) é calculado por meio do somatório do produto entre a razão de perda de solo (RPS) e a fração do índice de erosividade $\left(\mathrm{FEI}_{30}\right)$ de cada estádio do ciclo da cultura, como apresentado na Equação 6.

$$
\text { Fator } C=\sum R P S_{i} \cdot F E I_{30}=\sum \frac{\text { Fator } A_{m}}{{\text { Fator } A_{1}}_{1}} \cdot \frac{R_{i}}{R}
$$

em que:

Factor $C=$ uso e manejo do solo $\left(\left(\mathrm{Mg} \mathrm{ha}^{-1}\right) \cdot\left(\mathrm{Mg} \mathrm{ha}^{-1}\right)^{-1}\right)$;

$i=$ estádio da cultura;

$R S L_{i}=$ razão de perdas de terra no estádio i;

Factor $A_{m}=$ perda de solo no cultivo $\mathrm{m}\left(\mathrm{kg} \mathrm{ha}^{-1}\right)$;

Factor $A_{1}=$ perda de solo na parcela $1\left(\mathrm{~kg} \mathrm{ha}^{-1}\right)$;

$R_{i}=$ erosividade no estádio i $\left(\mathrm{MJ} \mathrm{mm} \mathrm{ha}{ }^{-1} \mathrm{~h}^{-1}\right)$;

$R=$ erosividade do ciclo $\left(\mathrm{MJ} \mathrm{mm} \mathrm{ha}{ }^{-1} \mathrm{~h}^{-1}\right)$.

O fator de práticas conservacionistas $(\mathrm{P})$ representa o efeito de práticas implantadas na área rural expressando a relação entre a perda de solo com determinada prática e a correspondente perda quando a cultura está implantada no sentido do declive (morro abaixo).

\subsection{Absorção acústica}

Após a incidência da onda sonora em um obstáculo, o som incidente (I) divide-se, principalmente, em som refletido (R), som absorvido (A) e som transmitido (T). 
O coeficiente de reflexão $\left(\mathrm{R}_{\mathrm{p}}\right)$ pode ser obtido a partir da relação entre o nível de pressão sonora incidente $\left(\mathrm{NPS}_{\mathrm{I}}\right)$ sobre uma superfície e o nível de pressão sonora refletida $\left(\mathrm{NPS}_{\mathrm{R}}\right)$ à superfície do material a ser testado, conforme apresentado na Equação 7.

$$
R_{p}=K \cdot \frac{N P S_{R}}{N P S_{I}}
$$

em que:

$$
\begin{aligned}
& R_{p}=\text { coeficiente de reflexão }(-) ; \\
& K=\text { constante para o espalhamento geométrico (-); } \\
& S P L_{R}=\text { nível de pressão sonora refletida }(\mathrm{dB}) ; \\
& S P L_{I}=\text { nível de pressão sonora incidente }(\mathrm{dB}) .
\end{aligned}
$$

De acordo com Kutruff (2009), a intensidade de uma onda plana é proporcional ao quadrado da amplitude de pressão. Portanto, a intensidade da onda refletida é menor por um fator $\left|R_{p}\right|^{2}$ do que a onda incidente. A fração $1-\left|R_{p}\right|^{2}$ da energia incidente é perdida durante a reflexão e esta quantidade também é chamada "coeficiente de absorção" da superfície. Para cada ângulo de reflexão $(\theta)$, $\alpha$ pode ser calculado usando a Equação 8.

$$
\alpha(\theta)=1-\left|R_{p}(\theta)\right|^{2}
$$

em que:

$\alpha(\theta)=$ coeficiente de absorção para diferentes ângulos de incidência;

$R_{p}(\theta)=$ coeficiente de reflexão para diferentes ângulos de incidência.

Em teste de sinais, o valor do coeficiente de absorção de uma superfície reflete as características físicas do material, sendo a variável analisada em muitas aplicações acústicas, principalmente no caso de atenuação sonora em campo aberto.

O sinal emitido para avaliar o coeficiente de absorção de uma superfície deve ter um comportamento sonoro conhecido. O ruído rosa tem a propriedade de ser um ruído constante através de todas as bandas de frequência, possuindo distribuição Gaussiana, garantindo que a mesma quantidade de energia estimule o sistema nas bandas analisadas (Everest e Pohlmann, 2009).

O nível de pressão sonora equivalente $\left(\mathrm{L}_{\mathrm{EQ}}\right)$, dos níveis de pressões incidentes $\left(\mathrm{NPS}_{\mathrm{I}}\right)$ e níveis de pressões refletidas $\mathrm{NPS}_{\mathrm{R}}$, como sugerido por Fracastoro (2003), é calculado utilizando a Equação 9.

$$
L_{E Q}=10 \cdot \log \left\lceil\frac{1}{t} \cdot \sum_{i=1}^{n} t_{i} \cdot 10^{\left(\frac{N P S i}{10}\right)}\right\rceil
$$

em que:

$L_{E Q}=$ Nível de pressão sonora equivalente $(\mathrm{dB})$;

$t=$ Período de amostragem (h);

$S P L_{i}=$ sound pressure level “i”" $(\mathrm{dB})$;

$t_{i}=$ Tempo parcial $(\mathrm{h})$. 


\section{MATERIAL E MÉTODOS}

\subsection{Monitoramento da perda de solo}

As parcelas experimentais de perda de solo (P) foram construídas seguindo as recomendações descritas por Wischmeier e Smith (1978). Em razão da área disponível para o estudo, foram construídas quatro parcelas erosivas delimitadas em alvenaria, com dimensões de $2,0 \mathrm{~m} \mathrm{x} 12,5 \mathrm{~m}$, correspondendo a $25 \mathrm{~m}^{2}$, proporcionais ao tipo "padrão" recomendado pela literatura. À jusante de cada parcela foi instalado um sistema coletor do escoamento superficial composto por calha direcionadora e tanque de sedimentação (S), com capacidade de $1000 \mathrm{~L}$.

O estudo foi conduzido nas proximidades do córrego Mandacaru, afluente da bacia hidrográfica do ribeirão Maringá, localizado a $23^{\circ} 24^{\prime} \mathrm{S}$ e $51^{\circ} 57^{\prime} \mathrm{W}$, na zona norte do município de Maringá - PR. A área de estudo está localizada em média-baixa vertente, a 500 metros de altitude, sobre um Nitossolo Vermelho Distroférrico latossólico, possui declividade de $9 \%$ e permaneceu em pousio de plantio por mais de cinco anos (Figura 1). A área encontra-se sob clima tipo Cfa, de Köppen, com precipitação média anual entre 1.250 a 1.500 $\mathrm{mm}$, verões quentes e chuvosos, invernos com menor índice pluviométrico, mas sem estação seca definida.

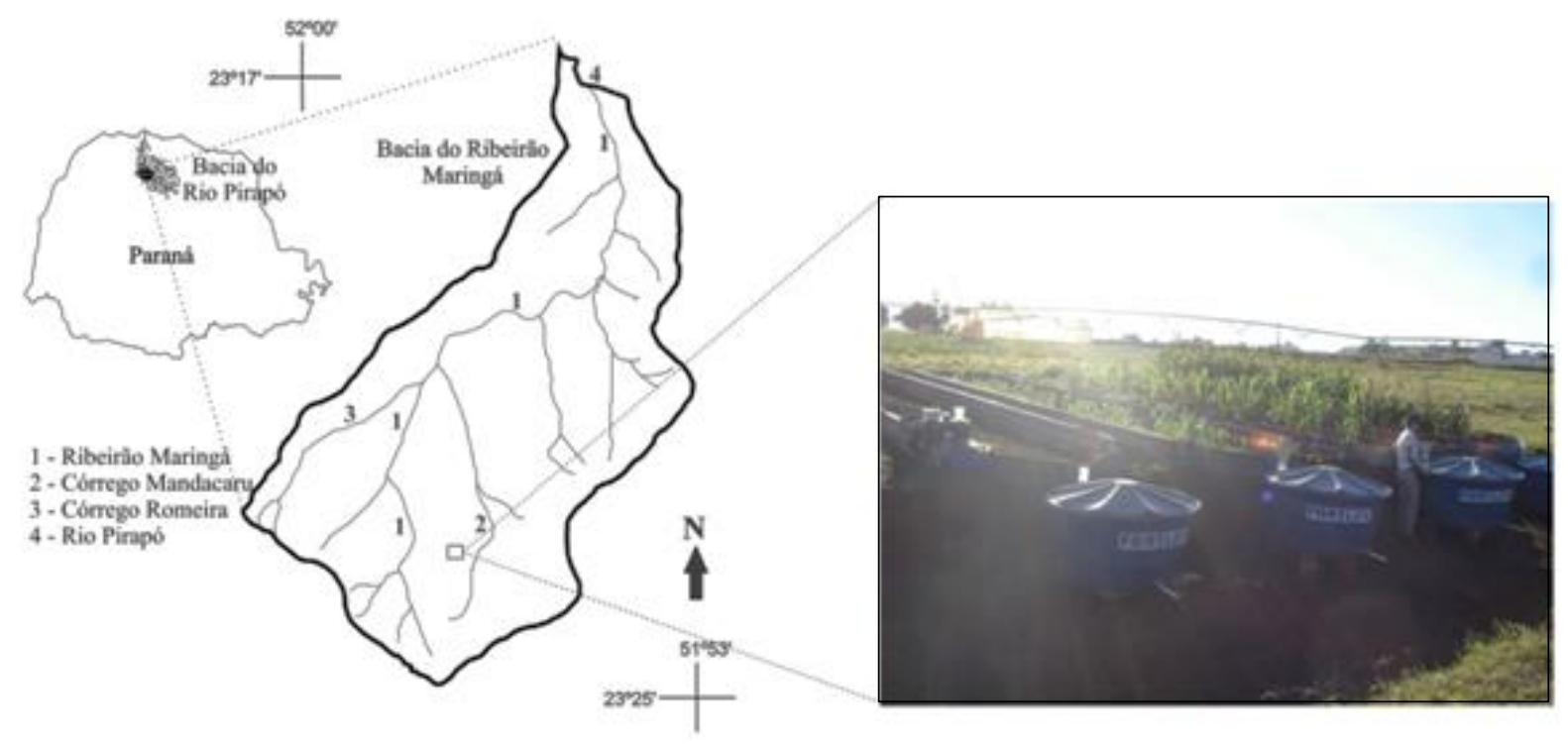

Figura 1. Localização da área de estudo.

O monitoramento da perda de solo foi realizado por meio de ciclos de cultivo, mantendo uma parcela com solo exposto (P1) e outra com vegetação (Brachiaria decumbens) (P2). Os ciclos foram compostos de culturas do período chuvoso (verão), com cultivo de milho (P3) e soja (P4), e culturas típicas do período de estiagem (inverno), com o cultivo do milho safrinha (P3) e trigo (P4).

As coletas de amostras de material transportado se totalizaram em seis campanhas no ciclo chuvoso e em sete campanhas no ciclo de estiagem, compreendendo o período de um ano. Em virtude do grande volume de água de escoamento superficial transportado para os sedimentadores (S) houve necessidade de realizar amostragem. Para tanto, realizou-se a raspagem do fundo dos sedimentadores, de modo a suspender os sedimentos, e prosseguiu-se a agitação do material com a finalidade de homogeneizar a solução água-solo e logo, coletar quantidade suficiente para as análises laboratoriais. 
Todas as amostras coletadas eram armazenadas em frascos de polietileno tereftalato (PET), anteriormente lavados. A sistemática de preservação das amostras seguiu a metodologia proposta em Standard Methods for Examination of Water and Wastewater (APHA, 1998).

A quantificação de solo transportado para cada sedimentador (S), em massa, seguiu o procedimento para a determinação de sólidos totais $\left(\mathrm{mg} . \mathrm{L}^{-1}\right)$, descrito em APHA (1998), sendo este resultado multiplicado pelo respectivo volume escoado encontrado em cada sedimentador.

A estimativa para a quantificação do volume da solução água-solo transportada para os sedimentadores foi realizada medindo-se a altura da lâmina d'água, com auxílio de trena. Posteriormente, essa medida foi aplicada na equação de volume, considerando que os sedimentadores possuem forma geométrica próxima a um cilindro.

A perda de sólidos totais por área da parcela experimental monitorada em relação ao volume escoado $\left(\mathrm{kg} \mathrm{ha}^{-1}\right)$ foi considerada numericamente equivalente ao Fator A da EUPS.

Logo após cada coleta amostral, os tanques eram esvaziados e lavados para que não houvesse a mistura com o material das chuvas subsequentes. As análises eram realizadas no Laboratório de Gestão, Controle e Preservação Ambiental (LGCPA), do Departamento de Engenharia Química da Universidade Estadual de Maringá (UEM).

Os dados de precipitação pluviométrica e de intensidade de chuva eram fornecidos pela Estação Climatológica da Universidade Estadual de Maringá (ECUEM), localizada a 1,8 km da área experimental, representando, portanto, satisfatoriamente as condições do local de estudo. Para a erosividade (Fator R), considerando o período de realização do experimento e o regime de chuvas, optou-se pelo equacionamento proposto em Bertoni e Lombardi Neto (2010). Para isso foram utilizadas as Equações 2 e 3.

A erodibilidade do solo (Fator $\mathrm{K}$ ) teve seu valor determinado experimentalmente em campo, nas condições da Parcela 1 (método direto), aplicando a Equação 4. Em prática, o fator topográfico (Fator LS) foi computado utilizando a Equação 5.

O fator de uso e manejo (Fator C) para as demais parcelas foi estimado por meio da relação entre a razão de perda de solo (RPS) e a fração do índice de erosividade $\left(\mathrm{FEI}_{30}\right)$, conforme a Equação 6. Quanto ao Fator P, nas parcelas de erosão não foram utilizadas quaisquer práticas conservacionistas. O plantio foi realizado morro abaixo, levando, portanto, a um valor do Fator P igual 1,0.

\subsection{Sistema acústico}

O sistema acústico era composto por equipamentos responsáveis pela emissão do som, tais como amplificador de potência (ONEAL ${ }^{\circledR}$, modelo OP-2000), alto-falante (NATTS ${ }^{\circledR}, 200$ W RMS), driver (SELENIUM ${ }^{\circledR}$, modelo D-250X) no qual emitia o ruído rosa. Este sistema era alimentado por uma bateria automotiva comum acoplada a um inversor de tensão $\left(\right.$ SMART $^{\circledR} 2000 \mathrm{~W}$ ), que promovia a conversão da voltagem de $12 \mathrm{~V}$ para $127 \mathrm{~V}$, utilizada pelos equipamentos.

Para emprego em campo, foi elaborado um suporte para sustentação do alto-falante, driver e medidor de nível de pressão sonora da onda incidente e refletida. O NPS I era coletado a uma distância de $0,3 \mathrm{~m}$ da fonte sonora em uma altura de $0,8 \mathrm{~m}$ em relação à base, enquanto que o NPS $\mathrm{R}_{\mathrm{R}}$ era coletado a uma distância de 2,0 m da fonte, em 1,00 m de altura (microfone à base). Para evitar a sobreposição de ondas incidentes e refletidas, a fonte sonora e o medidor acústico apresentavam uma inclinação de $42,5^{\circ}$ em relação à normal do suporte (Figura 2).

Em cada medição, o suporte contendo o sistema de emissão e recepção sonora foi posicionado no ponto central das parcelas por apresentar maior homogeneidade quanto à cobertura da superfície. 
Foi utilizado um sonômetro digital portátil da ICEL ${ }^{\circledR}$, modelo DL 4200, para medição do nível de pressão sonora da onda incidente e refletida $\left(\mathrm{NPS}_{\mathrm{I}}\right.$ e $\left.\mathrm{NPS}_{\mathrm{R}}\right)$. O equipamento utilizado é para medição de nível de pressão sonora de uso geral (classe 2), pois a ideia do trabalho era verificar o potencial de utilização de um equipamento de campo para estimar a capacidade de erosão. Em campo, foram aplicadas as seguintes configurações no equipamento: modo de coleta FAST, em escala dB C, com amplitude de 30 a $130 \mathrm{~dB}$, e durante um período total de 1 minuto e 30 segundos.

A)

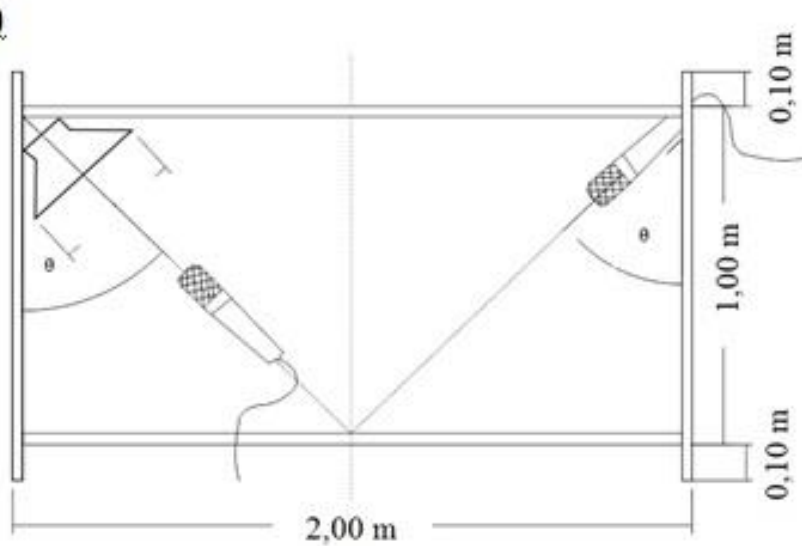

B)

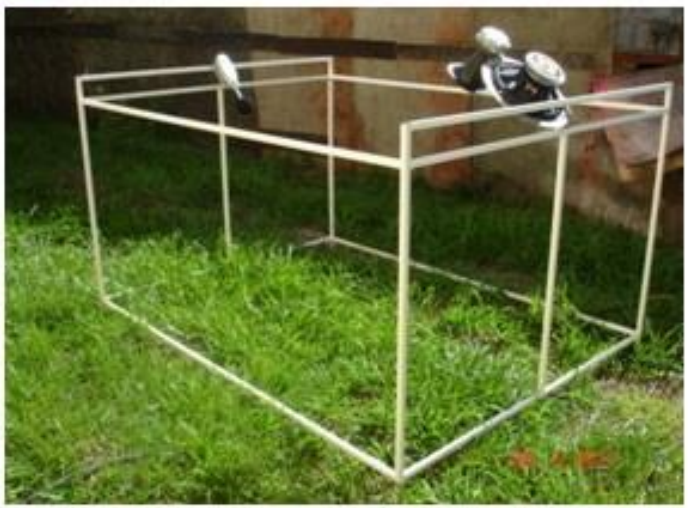

Figura 2. Disposição do suporte para sustentação do alto-falante, driver e medidor de nível de pressão sonora da onda incidente e refletida.

Os testes acústicos eram realizados o mais próximo possível da data de coleta do material transportado para os sedimentadores (S). No ciclo chuvoso foram realizadas quatro campanhas e na estiagem três campanhas. Os dados coletados eram armazenados no Data Logger do equipamento e foram processados por meio do cálculo do nível de pressão sonora equivalente $\left(\mathrm{L}_{\mathrm{EQ}}\right)$, dos níveis de pressões incidentes $\left(\mathrm{NPS}_{\mathrm{I}}\right)$ e níveis de pressões refletidas $\mathrm{NPS}_{\mathrm{R}}$, usando a Equação 9.

O efeito de cada cobertura das parcelas erosivas foi avaliado por meio do coeficiente de absorção sonora aparente da superfície $(\alpha)$ para a associação com os diferentes tipos de manejo e cobertura presentes nas parcelas. A Equação 7 (com $\mathrm{K}=1$ - adotado) e a Equação 8 foram utilizadas para o cálculo. Ressalta-se que não foi medida a profundidade de penetração da onda incidente no solo.

\subsection{Análise estatística}

Para associação das propriedades acústicas $(\alpha)$ com os fatores da EUPS, foram realizados testes de correlação entre o coeficiente de absorção sonora aparente $(\alpha)$ e os valores de perda de solo (A), Fator K e Fator C obtidos nas superfícies das parcelas monitoradas.

Por se tratar de poucos dados disponíveis, em razão dos testes realizados diretamente em campo, assumiu-se distribuição linear dos resultados encontrados permitindo o emprego do método de correlação de Pearson. Os coeficientes de correlação de Pearson foram determinados utilizando-se o software Statistica ${ }^{\circledR}$.

\section{RESULTADOS E DISCUSSÃO}

\subsection{Monitoramento da perda de solo}

Os dados de precipitação pluviométrica e das intensidades pluviométricas para cada mês em que houve coleta de dados encontram-se apresentados na Figura 3.

De acordo com os dados pluviométricos históricos, fornecidos pela ECUEM, o intervalo de março a agosto refere-se aos meses em que a precipitação pluvial não é tão marcante e, por 
isso, pode ser considerado como um período aqui denominado como estiagem. Para efeito do presente estudo, os meses de outubro a fevereiro foram considerados como chuvosos.

Considerando os dados pluviométricos para os anos de 2011 e 2012, foi observada uma irregularidade no regime de chuvas durante o período de trabalho, caracterizando uma atipicidade local, segundo informações da rede de monitoramento online do Centro de Previsão do Tempo e Estudos Climáticos do Instituto Nacional de Pesquisas Espaciais (CPTEC- INPE).

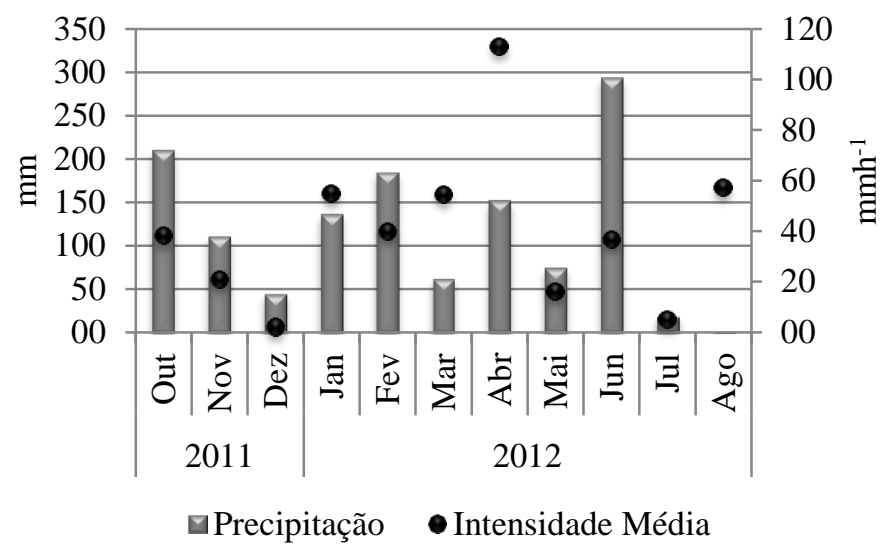

Figura 3. Precipitação pluviométrica $(\mathrm{mm})$ e intensidade da precipitação $\left(\mathrm{mm} \mathrm{h}^{-1}\right)$.

Em relação às intensidades das chuvas, os dados obtidos apresentaram grande variabilidade: em dezembro, caracterizado por ser um mês em que as chuvas são fortes e constantes, a intensidade máxima medida foi de $2,0 \mathrm{~mm} \mathrm{~h}^{-1}$; e, em abril ocorreram chuvas com intensidades de até $113,0 \mathrm{~mm} \mathrm{~h}^{-1}$. Com os resultados apresentados, destaca-se que a condição de atipicidade e a variabilidade dos dados pluviométricos se mostraram críticas na projeção dos resultados do efeito erosivo sob a ação da chuva.

A quantificação do material total e efetivamente transportado aos sedimentadores $\left(\mathrm{kg} \mathrm{ha}^{1}\right)$ e das demais variáveis que regem a EUPS estão apresentadas na Tabela 1. Estes resultados refletem de modo satisfatório o tipo de manejo aplicado neste período do experimento e refletem também os eventos atípicos de precipitação ocorridos.

No que se refere à carga transferida das vertentes da bacia ao curso d'água principal, considerando que a bacia do ribeirão Maringá possui aproximadamente 6.300 ha ocupados por área rural com predominância dos Nitossolos Vermelhos Distroférrico latossólico (Santos e Morais, 2012), no total foram exportados ao exutório da bacia 15.753,15 toneladas de solo provenientes das áreas agrícolas no período de estudo. Em geral, as perdas foram maiores na parcela com solo exposto $(91,5 \%)$, seguida pela parcela com cultivo de milho $(4,4 \%)$, soja/trigo $(2,5 \%)$ e, por ultimo, a parcela com pastagem $(1,6 \%)$. O período de estiagem foi aquele em que o transporte de massa ao longo da vertente foi mais intenso, em função a atipicidade pluviométrica.

Em relação à erosividade, é extremamente importante destacar que os índices de erosividade (FEI) e o fator de erosividade (Fator R) calculados correspondem unicamente aos efeitos da intensidade das chuvas ocorridas durante a realização dos trabalhos experimentais, obtendo-se 65,8 $\mathrm{MJ} \mathrm{mm} \mathrm{ha}{ }^{-1} \mathrm{~h}^{-1}$ no período chuvoso e de 74,3 $\mathrm{MJ} \mathrm{mm} \mathrm{ha}^{-1} \mathrm{~h}^{-1}$ no período de estiagem. De acordo com a classe de interpretação proposta por Silva et al. (2007), em geral, o grau da erosividade encontrado pode ser considerado "muito fraco".

Com inclinação da vertente em $9 \%$ e o comprimento de rampa de $12,5 \mathrm{~m}$, o fator topográfico (LS) estimado para as parcelas erosivas foi de 21,35. O valor total estimado para a erodibilidade (Fator $\mathrm{K}$ ), 16,3 $\mathrm{kg} \mathrm{h} \mathrm{MJ}^{-1} \mathrm{~mm}^{-1}$, mostrou-se dentro da faixa apresentada em 
Bertoni e Lombardi Neto (2010) para os Nitossolos. Westphalen (2007) alerta sobre a média resistência à erosão laminar que os Nitossolos argilosos apresentam devido aos mesmos estarem situados à média vertente, onde a ação das forças de escoamento são maiores.

Em relação ao uso e manejo (Fator C), observou-se a influência de cada tipo de cultura na perda de solo: a parcela com pastagem obteve total anual de $0,09 \mathrm{~kg} \mathrm{ha}^{-1} / \mathrm{kg} \mathrm{ha}^{-1}$; no período chuvoso a parcela 3 permaneceu com $0,59 \mathrm{~kg} \mathrm{ha}^{-1} / \mathrm{kg} \mathrm{ha}^{-1}$ e a parcela $4 \mathrm{com} 0,25 \mathrm{~kg}$ $\mathrm{ha}^{-1} / \mathrm{kg} \mathrm{ha}^{-1}$; no período de estiagem a parcela 3 permaneceu com $0,31 \mathrm{~kg} \mathrm{ha}^{-1} / \mathrm{kg} \mathrm{ha}^{-1}$ e a parcela 4 com $0,15 \mathrm{~kg} \mathrm{ha}^{-1} / \mathrm{kg} \mathrm{ha}^{-1}$. Em termos de manejo conservacionista, a presença de vegetação rasteira promoveu uma maior proteção ao solo.

Tabela 1. Variáveis da EUPS.

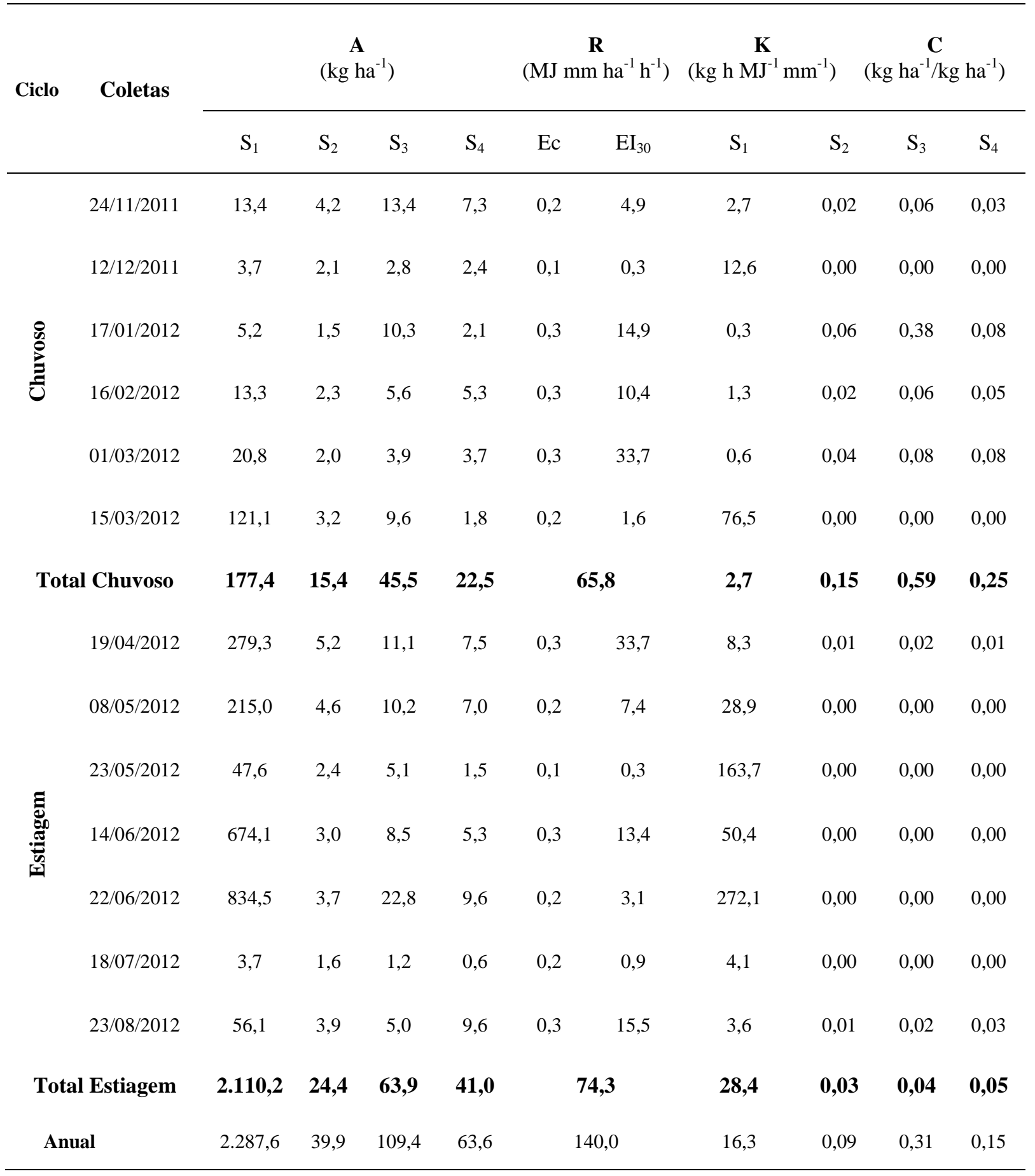

Nota: $S_{1}-$ sedimentador $1, S_{2}-$ sedimentador $2, S_{3}-$ sedimentador $3, S_{4}-$ sedimentador 4 . 


\subsection{Resposta acústica da superfície}

Os resultados obtidos no monitoramento acústico do nível de pressão sonora equivalente $\left(\mathrm{L}_{\mathrm{EQ}}\right)$, para os níveis equivalentes incidentes $\left(\mathrm{L}_{\mathrm{EQI}}\right)$ e aqueles refletidos $\left(\mathrm{L}_{\mathrm{EQR}}\right)$ pelas parcelas erosivas (P1, P2, P3 e P4), bem como os valores do coeficiente de absorção $(\alpha)$, calculados para as parcelas, encontram-se apresentados na Figura 4.

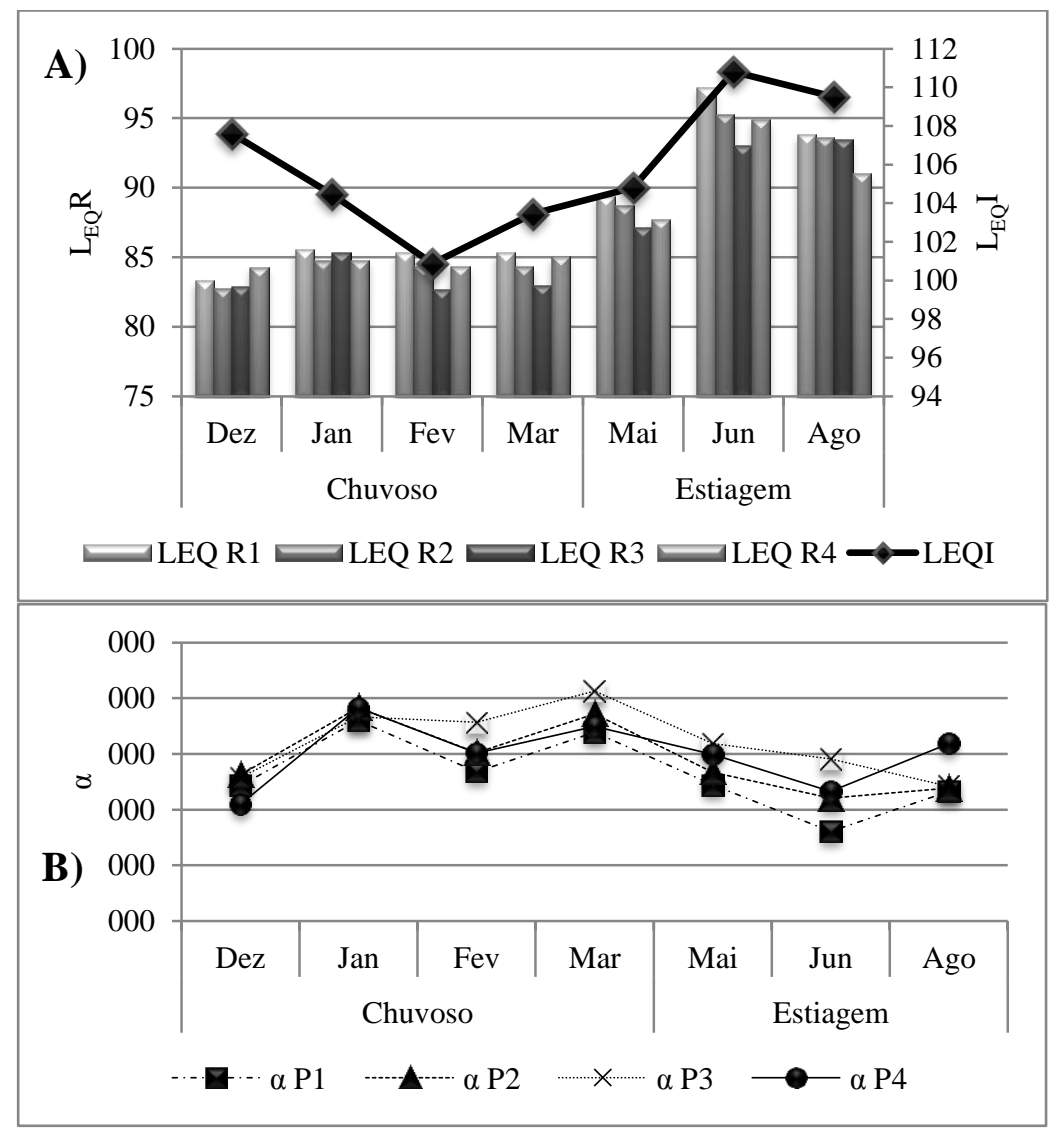

Figura 4. A) Nível de pressão sonora equivalente $\left(\mathrm{L}_{\mathrm{EQ}}\right)$ do sinal incidente (I) e refletido (R); B) Coeficiente de absorção sonora nas parcelas experimentais.

Inicialmente observou-se na Figura 4A que os valores obtidos para o $\mathrm{L}_{\mathrm{EQI}}$ não correspondem fielmente a uma quantidade constante de energia emitida, típica do ruído rosa. Os valores do $\mathrm{L}_{\mathrm{EQI}}$ permaneceram entre 103,4 e $110,8 \mathrm{~dB}$, apresentando variações ao longo do tempo; já os valores do refletida $\mathrm{L}_{\mathrm{EQR}}$, em geral, variaram entre 82,7 e 97,2 dB. É importante enfatizar que os valores do NPS $\mathrm{I}$ e do $\mathrm{NPS}_{\mathrm{R}}$ contem as interferências ambientais ocorridas durante a realização dos testes. $\mathrm{O}$ vento, por exemplo, sempre foi um fator presente durante a realização dos ensaios em campo. Contudo, os fatores ambientais atuantes, e de difícil controle para testes ideais, foram levados de forma positiva visto que a maioria dos trabalhos existentes sobre o assunto limita-se a escala laboratorial, onde as condições de controle não representam fielmente a dinâmica real do ambiente natural e que são de interesse para o presente trabalho.

A variação dos fatores ambientais contidas nos níveis sonoros estudados não prejudicou a confiabilidade dos valores obtidos com o cálculo do coeficiente de absorção in situ ( $\alpha$ ), pois os NPS $\mathrm{R}_{\mathrm{R}}$ foram medidos imediatamente após o NPS $\mathrm{I}$ e nas mesmas condições de campo.

Ao analisar os resultados apresentados foi possível observar a interferência dos fatores de atenuação na propagação do som, com o nível sonoro incidente sempre maior que o refletido. 
Entre esses efeitos cabe salientar a distância entre fonte e receptor, variações de umidade e temperatura do ar, bem como os efeitos do solo e presença de vegetação.

Analisando os coeficientes de absorção, Figura 4B, verificou-se que houve uma diferença na resposta entre as parcelas, durante o período de estudo, indicando o efeito entre as diferentes rugosidades das superfícies. As parcelas com a presença de pastagem e as parcelas com os cultivos apresentam valores de $\alpha$ diferenciam-se mês a mês. Tal diferença poderia ser justificada pelo desenvolvimento, tipo de folha, caule e crescimento da vegetação ao longo do tempo.

Segundo Bistafa (2011), a vegetação e o solo existentes entre a fonte e o receptor tanto podem absorver como também espalhar o som incidente em $\pm 3 \mathrm{~dB}$. Contudo, não foi observado um padrão de absorção que prevaleceu com o tempo de monitoramento e que reforçasse essa teoria para as condições estudadas.

Considerando que os ensaios foram realizados dentro de um período de um ano, é provável que os efeitos da umidade do ar, variação na direção dos ventos e os gradientes verticais de temperatura que ocorreram entre os testes acústicos tenham colaborado fortemente nos $\mathrm{L}_{\mathrm{EQR}}$ medidos $\mathrm{e}$, consequentemente, nos coeficientes $\alpha$ estimados. As condições ambientais locais, cujo controle é impraticável em campo, contribuíram para que não houvesse uma distinção clara ao longo do tempo de monitoramento entre os coeficientes de absorção sonora e o tipo de cobertura instalada nas parcelas.

Em média, o solo exposto (P1) apresentou o menor valor de absorção $(0,26)$ e, entre as parcelas com cultivo, a superfície com cultura do milho (P3) apresentou o maior coeficiente de absorção $(0,32)$, seguida pela cultura de soja/trigo $(0,31)$ e pastagem $(0,31)$.

\subsection{Correlação entre os fatores da EUPS e os coeficientes de absorção.}

Os coeficientes de correlação entre absorção acústica e alguns fatores da EUPS para cada ciclo de experimento encontram-se na Tabela 2, destacados em negrito.

Tabela 2. Coeficientes de correlação entre $\alpha$ e variáveis da EUPS

\begin{tabular}{ccccccccc}
\hline \multicolumn{7}{c}{ Período Chuvoso } \\
\hline & $\mathrm{A}_{1}$ & $\mathrm{~A}_{2}$ & $\mathrm{~A}_{3}$ & $\mathrm{~A}_{4}$ & $\mathrm{k}_{1}$ & $\mathrm{C}_{2}$ & $\mathrm{C}_{3}$ & $\mathrm{C}_{4}$ \\
\hline$\alpha_{1}$ & $\mathbf{0 , 4 1}$ & $-0,80$ & 0,87 & $-0,56$ & $\mathbf{0 , 3 3}$ & 0,53 & 0,65 & 0,37 \\
$\alpha_{2}$ & 0,48 & $\mathbf{- 0 , 7 3}$ & 0,86 & $-0,50$ & 0,37 & $\mathbf{0 , 4 9}$ & 0,59 & 0,37 \\
$\alpha_{3}$ & 0,70 & $-0,26$ & $\mathbf{0 , 6 1}$ & $-0,20$ & 0,53 & 0,21 & $\mathbf{0 , 5 0}$ & 0,22 \\
$\alpha_{4}$ & 0,36 & $-0,65$ & 0,91 & $\mathbf{- 0 , 4 5}$ & 0,20 & 0,62 & 0,65 & $\mathbf{0 , 5 6}$ \\
\hline & & & $\mathbf{P e r i ́ o d o ~ d e ~ E s t i a g e m ~}$ & & & \\
\hline & $\mathrm{A}_{1}$ & $\mathrm{~A}_{2}$ & $\mathrm{~A}_{3}$ & $\mathrm{~A}_{4}$ & $\mathrm{k}_{1}$ & $\mathrm{C}_{2}$ & $\mathrm{C}_{3}$ & $\mathrm{C}_{4}$ \\
\hline$\alpha_{1}$ & $\mathbf{- 0 , 9 9}$ & $-0,05$ & $-0,99$ & $-0,09$ & $\mathbf{0 , 3 6}$ & 0,32 & $-0,60$ & 0,35 \\
$\alpha_{2}$ & $-0,80$ & $\mathbf{- 0 , 5 4}$ & $-0,78$ & $-0,57$ & 0,77 & $\mathbf{- 0 , 1 9}$ & $-0,92$ & $-0,16$ \\
$\alpha_{3}$ & 0,15 & $-1,00$ & $\mathbf{- 0 , 1 9}$ & $-0,99$ & 0,92 & $-0,96$ & $\mathbf{- 0 , 7 8}$ & $-0,95$ \\
$\alpha_{4}$ & $-0,97$ & 0,29 & $-0,98$ & $\mathbf{0 , 2 6}$ & 0,02 & 0,63 & $-0,29$ & $\mathbf{- 0 , 6 5}$ \\
\hline
\end{tabular}


Nesse estudo, foram encontradas correlações fracas-moderadas entre $\alpha$ e o Fator A, com valores em módulo variando entre 0,41 e 0,73 no período chuvoso e valores variando entre 0,19 e 0,99 no período de estiagem. Entre $\alpha$ e o Fator C, os valores em módulo variaram entre 0,49 a 0,56 para o período chuvoso, indicando relação matemática diretamente proporcional, e entre $-0,19$ e $-0,78$ no período de estiagem, indicando relação matemática inversamente proporcional. Entre $\alpha$ e o Fator K, os coeficientes de correlação obtidos no período chuvoso e no de estiagem puderam ser considerados como "fraco", com valores variando entre 0,33 e 0,36 .

A partir dos resultados apresentados, não é possível obter uma explicação plausível para os fenômenos realmente atuantes no processo de absorção sonora utilizando para o cálculo o valor de $\mathrm{L}_{\mathrm{EQ}}$ e as variáveis envolvidas no processo de perda de solo. É muito provável que, além das condições de atipicidade pluviométrica, condições atmosféricas (vento, umidade), a condição de saturação do solo no momento da realização dos ensaios tenha sido um fator determinante, como constatado em Sharma e Gupta (2010). De acordo com Lo et al. (2007), a condição de saturação pode estar relacionada ainda à outras propriedades físicas do solo, tal como a condição de porosidade, permeabilidade e densidade do solo, que não foram medidas em campo no momento do ensaio o que, contudo, abre espaço para novas pesquisas na área.

Considerando a metodologia adotada no presente trabalho, apesar dos resultados não se apresentarem favoráveis para concepção da técnica acústica na predição dos fatores de perda de solo, é possível haver alguma relação entre os efeitos da incidência de uma onda acústica conhecida sobre diferentes rugosidades de superfície agrícolas considerando o espectro de frequência acústico. Os pequenos comprimentos de onda, característicos de alta freqüência, podem sensibilizar mais adequadamente à superfície em estudo e reproduzir resultados mais satisfatórios. Trabalhos futuros devem ser desenvolvidos sobre essa perspectiva.

\section{CONCLUSÃO}

Considerando que o presente estudo foi realizado em um período de eventos atípicos de precipitação pluviométrica, 91,5\% dos materiais transportados foram oriundos da parcela com solo exposto, 4,4\% foram do cultivo de milho, $2,5 \%$ foram da cultura de soja/trigo e 1,6\% foram da área com pastagem.

O Fator R total computado refletiu de modo satisfatório as observações feitas em campo. $\mathrm{O}$ Fator K permaneceu dentro da faixa típica da classe Nitossolos e indica um solo com média resistência aos processos erosivos. O cálculo do Fator $\mathrm{C}$ indicou a potencialidade do cultivo de milho e soja/trigo em relação à perda de solo nas parcelas.

Em relação à análise acústica das superfícies e considerando a metodologia adotada, os resultados apontaram que não houve grande diferenciação entre o coeficiente de absorção acústico e o tipo de cobertura do solo das parcelas erosivas.

\section{REFERÊNCIA}

AMERICAN PUBLIC HEALTH ASSOCIATION - APHA. Standard methods for the examination of water and wastewater. Washington, 1998. 1600p.

BERTONI, J.; LOMBARDI NETO, F. Conservação do solo. 4. ed. São Paulo: Ícone, 2010. $355 \mathrm{p}$.

BISTAFA, S. R. Acústica aplicada ao controle do ruído. São Paulo: Edgard Blücher, 2011. $384 \mathrm{p}$. 
CAROLINO de SÁ, M. A.; LIMA, J. M.; MELLO, C. R. Nível de energia ultrassônica para estudo da estabilidade de agregados de um latossolo sob diferentes usos. Pesquisa Agropecuária Brasileira, v. 37, p. 1649-1655, 2002. http://dx.doi.org/10.1590/S0100204X2002001100017

CHAMBERS, J. P.; SABATIER, J. M. Recent advances in utilizing acoustics to study surface roughness in agricultural surfaces. Applied Acoustics, v. 63, p.795-812, 2002. http://dx.doi.org/10.1016/S0003-682X(01)00057-3

EVEREST, F. A.; POHLMANN, K. C. Master handbook of acoustics. 5. ed. New York: Mc Graw-Hill, 2009. 510p.

FRACASTORO, G. V. Física tecnica ambientale. Parte III: acustica aplicata. Progetto Didattica in Rete. Dipartamento di Energetica. 1. ed. Torino: Otto, 2003. 39p.

KUTRUFF. H. Room acoustics. 5. ed. Spon Press, 2009. 389p.

LO, W. C.; YEH, C. L.; TSAI, C. T. Effect of soil texture on the propagation and attenuation of acoustic wave at unsaturated conditions. Journal of Hydrology, v. 38, p. 273-284, 2007. http://dx.doi.org/10.1016/j.jhydrol.2007.02.034

RIBEIRO, B. T.; LIMA, J. M.; MELLO, C. R.; CAROLINO de SÁ, M. A., OLIVEIRA, G. C. Relationship between raindrops and ultrasonic energy on the disruption of a Haplic Cambisol. Ciência e Agrotecnologia, v. 33, p. 814-823, 2009. http://dx.doi.org/10.1590/S1413-70542009000300021

SANTOS, M. L.; MORAIS, E. S. Produção de sedimento na bacia hidrográfica de pequena ordem: uso de modelos matemáticos, bacia do Ribeirão Maringá, Paraná - Brasil. Revista Brasileira de Geomorfologia, v. 13, p. 139-150, 2012.

SHARMA, R. K.; GUPTA, A. K. Continuous wave acoustic method for determination of moisture content in agricultural soil. Computers and Eletronics Agriculture, v. 73, p. 105-111, 2010. http://dx.doi.org/10.1016/j.compag.2010.06.002

SILVA, A. M.; SCHULZ, H. E.; CAMARGO, P. B. Erosão e hidrossedimentologia em bacias hidrográficas. São Carlos: RiMa, 2007. 153p.

VITORINO, A. C. T.; FERREIRA, M. M.; OLIVEIRA, G. C.; JÚNIOR, M. C.; CAROLINO de SÁ, M. A.; LIMA, J. M. et al. Níveis de energia ultrassônica na dispersão de argila em solos da região de Lavras (MG). Ciência e Agrotecnologia, v. 25, p. 1330-1336, 2001.

WESTPHALEN, L. A. Avaliação e classificação da erodibilidade dos solos do noroeste do Estado do Paraná: subsídio ao uso e ocupação da terra. Revista Eletrônica do Programa de Pós-Graduação em Geografia, v. 2, p. 42-42, 2007.

WISCHMEIER, W. H.; SMITH, D. D. Predicting rainfall erosion losses: a guide to conservation planning. Washington: U. S. Department of Agriculture, 1978. 67p. (Agriculture Handbook, n. 537). 